
Capítulo 1 



\title{
A vueltas con la memoria. Por una comunicación y documentación con base crítica
}

\author{
Juan-Francisco Torregrosa Carmona
}

La memoria constituye un ámbito central tanto para el individuo como para cualquier colectividad dada. En las siguientes líneas se aportan algunos elementos para el debate público sobre aquella. En el caso de la documentación, parcela claramente integrada a las ciencias de la información y la comunicación, esta es la esencia misma de la propia disciplina documental y la actividad profesional correspondiente. No en vano se ha dicho que la documentación es la memoria del periodismo, pero es una memoria lábil, precaria, con ritmos de trabajo y pautas de producción tanto de medios impresos como digitales, que no siempre favorece la reflexión y la profundidad sobre los temas abordados. De ahí que se reivindique como imprescindible una perspectiva crítica característica tanto del propio profesional como de la lectura social de sus discursos y narrativas mediáticas.

La consideración de la documentación como memoria, y de la memoria en sí misma, ha suscitado el interés de autores como García-Gutiérrez (1994). Este, junto con Martínez Ávila (2014), ha abogado por la necesidad de una formación crítica por parte de los documentalistas en los medios de comunicación, y ha manifestado la escasez de este enfoque en los manuales españoles sobre la materia. El propio García-Gutiérrez ya había alertado sobre el hecho de que las disciplinas que se han ocupado de registrar la memoria, como la biblioteconomía (o bibliotecología), la documentación, la archivística o la museografía, lo han venido haciendo desde unas posiciones netamente tecnicistas y mercantilistas.

* Profesor titular de Periodismo, Universidad Rey Juan Carlos (Madrid). Correo electrónico: juanfrancisco. torregrosa@urjc.es 
Sobre la memoria como objeto de estudio, cabe destacar, desde el ámbito historiográfico y sociológico, a Aróstegui (2004), a Cruz (2005) y, con particular brillantez, a Todorov (2002), cuya obra Memoria del mal, tentación del bien. Indagación sobre el siglo $X X$ resulta recomendable.

Entre los lugares de la memoria, internet aparece como el nuevo espacio central: al principio, una inmensa isla, y, hoy, una utopía redefinida, superada a sí misma por la realidad del desarrollo económico, tecnológico y social en las naciones más avanzadas. Algunos autores creativos del idioma se han apropiado del neologismo glocal para definir una nueva época que es posible y probable que no haya hecho sino comenzar, con la influencia y la presencia de los más diversos territorios.

Si la memoria personal es la representación que hacemos de nuestro pasado, la memoria colectiva - léase mediática- es la representación - la construcción diaria - de nuestro común presente. Como destaca José Vidal-Beneyto (2006), "hace ya años que un grupo significativo de analistas de la comunicación afirmamos que los periodistas no daban cuenta de la realidad, sino que la producían".

No hay duda de que, en parte debido a la influencia de los medios de comunicación, vivimos una época de intersección de fronteras. Internet, paradigma de la información y de encuentros transfronterizos, y exponente de lo virtual por oposición a lo físico, tiene su correlato demográfico en el auge de las sociedades multiculturales, a las que empezó a sumarse la española, a mediados de la década de los noventa, en un innegable paralelismo con los primeros pasos de la red como realidad en el país. Si bien ya ha habido una mejora, España es de los países europeos donde el índice de penetración y uso de internet en la vida cotidiana de la ciudadanía en general ha sido relativamente bajo hasta hace poco.

Los conceptos tiempo y distancia cobran un nuevo valor, tanto en lo material como en lo psicológico, dentro de un proceso que no es exclusivo de la comunicación, sino que afecta a cualquier aspecto que tenga que ver con lo humano. Un ejemplo son los movimientos migratorios de personas que recorren cientos y cientos de kilómetros en busca de una vida mejor. Por lo tanto, se puede comprobar que la relación entre la sociedad multicultural y el mundo interconectado por los satélites y las redes de comunicación no es solo una metáfora, sino también una analogía real que confirma la difuminación de fronteras, tanto geográfico-convencionales, como imaginarias. Y es que la circulación de la información y la documentación hacia puntos cada vez más distantes, y en tiempo real, gracias a la red de redes, es hoy una posibilidad cuya materialización ya no nos asombra, pese a la magnitud del fenómeno y a su reciente aparición considerada en términos históricos.

Las migraciones van unidas a la identidad y a la memoria. El cambio de territorio de residencia implica un claro ejercicio memorístico en relación con 
lo vivido en el lugar de origen hasta ese momento. También afecta la identidad y las expectativas del sujeto, para quien el país de origen y el de acogida son elementos vitales de primer orden. Cuántas veces no se ha apelado a la memoria colectiva (valga la expresión) que debe conservar ante este tema capital (como elemento influyente en las praxis de los comportamientos) un país receptor de migrantes que hace unos pocos decenios fue emisor. En el caso concreto que aquí se enuncia, la memoria opera, en principio, como una facultad individual que se convierte - en virtud de su variada semántica - en una suerte de elemento social, compartido, que nos aleja - o se pretende-de fantasmas como la actitud velada o explícitamente racista ante el espejo humano de lo que fuimos. El Premio Nobel de Literatura José Saramago (2001) lo expresa con acierto: "Aquel que antes fue explotado y perdió la memoria de haberlo sido, acabará explotando a otro. Aquel que antes fue despreciado y finge haberlo olvidado, refinará su propia capacidad de despreciar. Aquel a quien humillaron, humillará con más rencor" (p. 12). Desde el ámbito de la biología, el Premio Nobel de Medicina Eric Kandel (2007) asevera que

[...] en razón de las implicaciones que tiene la biología mental para el bienestar individual y social, el consenso general de la comunidad científica indica que en el siglo XXI esa disciplina ocupará un lugar de preeminencia similar al que la biología del gen tuvo en el siglo XX. (p. 65)

Particularmente polémicos -o complejos - se muestran algunos conceptos periodísticos, políticos, e incluso legislativos, en España, como los de memoria histórica, por lo que han sido sometidos a un intenso debate ideológico, no solo respecto a su oportunidad y legitimidad, sino también a las ideas de justicia, derechos y dignidad humana ligadas a acontecimientos y a protagonistas - casi siempre dramáticos - del pasado: la Guerra incivil (1936-1939) y los casi cuarenta años de represión de la Dictadura de Franco, en cuya reparación moral trabajan, en principio, la asociaciones de familiares de víctimas del franquismo. No debemos olvidar que ya un autor como Todorov (2002) advirtió que la memoria debe ser sometida a la justicia, que es el verdadero objetivo social.

Sin dejar la evidente relación de la memoria y del pasado con los estudios históricos, Terán (2000) ha recordado cómo Nietzsche argumentaba que una sobreabundancia de estudios sobre el pasado solo podía acarrear un efecto pernicioso para la vida y para las sociedades, puesto que una inmoderada atención intelectual y académica a los hechos pretéritos impedía ocuparse del presente y del futuro, porque lastimaba la elogiable facultad del olvido, y ese exceso de memoria bloqueaba el pensamiento crítico y la creatividad.

En ocasiones, la reinterpretación, a la luz de los nuevos días y los sucesos actuales, de lo almacenado en los mecanismos que la biología humana proporciona, llega a alcanzar dimensiones que cambian radicalmente la memoria de lo vivido 
en tiempos pretéritos; por expresarlo de alguna manera, se convierte en nuevos recuerdos de viejos sucesos.

Como bien titula uno de sus libros de poemas Mario Benedetti (1995), El olvido está lleno de memoria. Cabría añadir que también la memoria y las memorias están llenas de olvido y de olvidos. En concreto, merece la pena recordar el poema ¿Cosecha de la nada? del autor uruguayo (2017):

Hay quienes imaginan el olvido como un depósito desierto / una cosecha de la nada y sin embargo el olvido está lleno de memorial hay rincones del odio por ejemplo con un rostro treinta veces ardido/ y treinta veces vuelto a renacer/ como otro ave fénix del desahucio/ hay arriatas de asombro/ con azahares sedientos de rocío / hay precarias lucernas del amor/ donde se asoman cielos que fueron apagados/ por la huesuda o por la indiferencia/ y sin embargo siguen esperando/ aunque nada ni nadie los desangre en voz alta/ ni el desamparo ni el dolor se borran y las lealtades y traiciones giran/ como satélites del sacrificio/ en el olvido encallan buenas y malas sombras/ huesos de compasión/ sangre de ungüentos/ resentimientos inmisericordes/ ojos de exilio que besaron pechos/ hay quienes imaginan el olvido/ como un depósito desierto/ una cosecha de la nada/ y sin embargo el olvido está lleno de memoria.

La relación de la literatura con las memorias y sus evocaciones es indiscutible. Desde muchos de los grandes títulos de la Antigüedad grecolatina, hasta las obras más difundidas del realismo mágico, con autores como el gran Nobel colombiano Gabriel García Márquez, o la chilena Isabel Allende, la presencia de la memoria de los sueños, los anhelos por olvidar episodios trágicos o turbios, los recuerdos infantiles, la proyección presente del pasado... son temas, desde el mundo onírico o desde otros muchos, cuya huella, con sutileza o abiertamente, es visible.

Pero, sin duda, el más conocido es el episodio de la magdalena de Proust, que cada vez que volvía a tomar un bollo, para mojarlo en el té, sentía volver, de golpe, el tiempo gozoso de la niñez. En este caso, al asociar ideas y recuerdos de forma involuntaria a determinadas sensaciones, las dimensiones emocional y racional de la memoria se dan la mano - aun cuando muchos autores insisten en lo artificial, e incluso erróneo por inseparable, de contraponer idea y razón, pensamiento y sentimiento-. Como bien observa García Gutiérrez (2004),

[...] es curioso cómo solemos dicotomizar nuestras actitudes y acciones en racionales e irracionales, adscribiendo al raciocinio unas propiedades específicas y relegando a la irracionalidad todo un universo complejo y rico de constelaciones de sensaciones, emociones e instintos, cada una de ellas tan potente como la racionalidad, cada una de ellas tan concretamente humanas como la razón. Sólo la razón simplificadora es la causa de su propia autosobrevaloración en función del menosprecio de un instinto y de una sensibilidad humanos únicos y diferenciadores respecto a otras especies. (p. 17) 
La doctrina destaca que el alcance de la obsesión de Marcel Proust (1871-1922) por recobrar el pasado es difícil de superar, como lo demuestra el hecho de que ninguna otra obra literaria esté más ligada a la memoria humana que $\grave{A}$ la recherche du temps perdu (En busca del tiempo perdido, 1913). El escritor lo expresó en las siguientes palabras (2016):

Pero cuando nada subsiste ya de un pasado antiguo, cuando han muerto los seres y se han derrumbado las cosas, solos, más frágiles, más vivos, más inmateriales, más persistentes y más fieles que nunca, el olor y el sabor perduran mucho más, y recuerdan, y aguardan, y esperan, sobre las ruinas de todo, y soportan sin doblegarse en su impalpable gotita el edificio enorme del recuerdo. (p. 40)

Volviendo a la literatura en lengua española, el poeta de Campos de Castilla también mencionó en su obra los recuerdos primeros. Como apunta el escritor Antonio Rodríguez Almodóvar (2005),

[...] no tuvo mucha suerte Antonio Machado con la ciudad que le vio nacer. Mas no por eso dejó de llevarla siempre en su corazón. A los ocho años de edad, en lo mejor de la infancia, tuvo que dejar atrás aquel relumbre de luz paradisíaca que maduraba en los limoneros del Palacio de las Dueñas. La luz de Sevilla, la que le acompañó en el recuerdo hasta el último momento. En un bolsillo del gastado gabán que había soportado el tránsito de los Pirineos, huyendo de la horda fascista, fue hallado el último verso que escribiera el poeta: Estos días azules y este sol de la infancia. También una variante de una de las cuartetas a Guiomar, su grande y secreto amor. No pudo ser casual esa asociación de última hora entre el huerto claro de la niñez y el jardín prohibido de un amor otoñal. Ni fue la primera vez que se daba.

Otro ejemplo es el texto de Jorge Luis Borges Funes el memorioso, quien, debido al exceso de memoria, no es capaz de pensar. La vieja idea de la precariedad del exceso, que tan bien podría aplicarse a la ingente producción informativa y documental actual, y a la necesidad de su evaluación y selección críticas.

Se podría decir que, con la memoria al centro, construimos (también) nuestra propia identidad y la que otorgamos a los demás. En esta misma línea, el ensayista Manuel Cruz (1995) lo expresa de la siguiente forma:

Alguien escribió que la memoria es ese don que nos consiente tener reunida nuestra vida, y llevaba casi toda la razón. Decimos "casi" porque la memoria, además de tener reunida nuestra vida - lo que no es poco-, la tiene ordenada. La memoria no conserva ni almacena, sino que destaca, señaliza, llama la atención. De ahí el tópico de su carácter cualitativo. Es el lápiz que subraya acontecimientos, momentos, personas que nos han hecho ser quienes somos y que han hecho de nuestro mundo lo que ahora es. Con otras palabras, cuando 
decimos de alguien que nos importa tanto que ha pasado a formar parte de nuestra memoria, estamos afirmando algo más importante que la constatación de que está instalado entre nuestros mejores recuerdos: estamos afirmando que ha contribuido, de manera decisiva, a darles sentido. (p. 155)

Respecto al ámbito colectivo, si nos remitimos a la hipernombrada sociedad de la información, con internet a la cabeza, no deja de ser paradójico y algo sorprendente que frente a las mayores posibilidades de archivo y registro documental, lo propio de los medios de comunicación sea, en tantas ocasiones, el relato espectacular y, sobre todo, efímero. Sin solución de continuidad, un hecho relevante queda desplazado por otro en cuestión no ya de días, sino de horas. Así, la memoria que cabría obtener o aprehender de los medios es cada vez más débil.

La sobreabundancia de producción informativa, y también su nueva forma de consumo - en realidad no tan nueva, pero sí mucho más acentuada de lo que antaño lo fue-, fragmentaria, descontextualizada muchas veces, muy limitada desde el punto de vista espacio-temporal, e incluso de su aporte documental, con una hibridación entre contenidos informativo-periodísticos y publicitario-propagandísticos..., hacen que se materialice la vieja metáfora: "El árbol no nos deja ver el bosque".

Si bien aquellas características tecnológicas y narrativas han hecho parte de la naturaleza de los medios audiovisuales, y de los vehiculados en todo tipo de soporte, desde sus inicios, nunca lo había sido como hoy, dada la saturación mediática que domina nuestros días, como ha destacado Todd Gitlin (2005), entre otros autores, en su obra, de significativo título, Enfermos de información. De cómo el torrente mediático está saturando nuestras vidas.

Paralelamente a la insoslayable amnesia que implica una cantidad de estímulos que no somos capaces de retener en el almacén-linterna personal de nuestra memoria, el modelo mediático que define a la sociedad pasa también por un tratamiento de la actualidad, en la que los secretos - o supuestos secretos-, tan relacionados con la memoria y con la identidad, desempeñan un papel decisivo y central. Así, es cada vez más frecuente acudir a hemerotecas y archivos de prensa para rescatar antiguas noticias o viejos reportajes - en definitiva, episodios controvertidos o incluso escabrosos - para los programas llamados "del corazón" o "de la prensa rosa" - en su vertiente televisiva-. Con la pretensión de polemizar, y bajo una lente sepia, aquellos traen a la memoria sucesos y protagonistas del pasado cuya relación con el presente, muchas veces, no es más que un vínculo construido por el discurso informativo de los propios medios. Muchos hablan de toda una "industria de la nostalgia”. Según Emilio Temprano (2002),

[...] hoy vivimos en plena orgía de desvelar nuestros secretos más personales, incluso con micrófonos y cámaras de televisión por medio. El mercado de la opinión pública reclama nuevos secretos y parece ser que siempre se está 
dispuesto a cubrir esa demanda. Las masas telemáticas quieren entretener su tedio, después de "un día agotador", con las confidencias de otros porque la sociedad de consumo también desea consumir secretos, y les encanta que las personas los descubran y expongan a la luz pública como una forma de extraña terapia y para olvidar sus propios problemas. (p. 67)

En el contexto actual, sobran ejemplos cercanos - pero también muchos históricos- que muestran la necesidad de una lectura crítica de la información audiovisual y de los contenidos de la red, así como de una consideración de la credibilidad de los medios o de lo que se les atribuye. En palabras del catedrático de la Universidad de Harvard Daniel Schacter (1999),

[...] los recuerdos más importantes de la sociedad residen ahora en los archivos electrónicos de los medios de comunicación de masas, no en las cabezas de rememorantes y narradores individuales. Ante tamañas cantidades de información codificada electrónicamente y disponible en todo momento, la función de conservación que desempeñaban los relatos que los ancianos contaban y los conocimientos que impartían ha perdido en buena medida su razón de ser. Sin embargo no tiene por qué ser así. Los intensos esfuerzos por localizar y grabar en vídeo las historias orales de los supervivientes del Holocausto ponen los recuerdos personales de los ancianos en contacto directo con la tecnología contemporánea de almacenamiento externo. Las narraciones autobiográficas de estos ancianos quizá logren alcanzar, a través de las narraciones electrónicas, la inmortalidad que antaño confería el método más tradicional de la transmisión oral. Y preservar testimonios de miles de rememorantes puede ayudar a garantizar que el olvido y la deformación (que pueden infiltrarse en cualquier narración individual de un recuerdo) se vean contrarrestados por las abrumadoras verdades que emergen de los elementos esenciales que tienen en común sus respectivos relatos. (p. 435)

\section{Algunas pinceladas de memoria sobre la historia del siglo $\mathrm{XX}$ y el papel de la comunicación y los medios}

Schacter introduce un tema esencial en relación con la memoria y con todas las formas y soportes documentales posibles para su registro. Si en el ámbito médico-biológico los casos de la terrible enfermedad de Alzheimer no paran de aumentar, a escala social existe una muestra de lo que el investigador denomina "El frágil poder de la memoria": que más de cincuenta años después del horror de los campos de exterminio nazis todavía haya significativos grupos de revisionistas que intentan negar el recuerdo colectivo de la mayor barbarie cometida por el ser humano en la era contemporánea. Ello, pese al testimonio de los 
supervivientes (muy pocos ya, dato que debe ser tenido muy en cuenta) y a las abundantes y fehacientes pruebas, como las imágenes de archivo en movimiento y la documentación fotográfica de la época, entre la que ocupa un valor mundial destacado el conjunto de fotografías captadas clandestinamente por el superviviente español Francesc Boix.

Como lo ha considerado Jorge Semprún (2001), otro español que sufrió el internamiento en un campo de concentración, cuando la voz y la memoria de los testigos se hayan extinguido, las fotografías seguirán alumbrando la memoria.

Para quienes deseen profundizar al respecto, el excelente libro de Alejandro Baer El testimonio audiovisual. Imagen y memoria del Holocausto, publicado en 2005 por el Centro de Investigaciones Sociológicas de España, además de trabajar la cultura de la memoria, aporta un estudio concreto sobre el papel de aquella en la tradición judía.

El presidente de Irán hasta el verano de 2013, el ultraconservador Mahmud Ahmadineyad, negó de plano la existencia del genocidio nazi, en el que murieron unos seis millones de judíos y miles de gitanos. Para el político radical, el Holocausto sería un "mito inventado por Occidente". Cabe recordar, como dato de contexto, que en Alemania y Austria la negación del Holocausto está sancionada con penas de prisión, y ha habido personas, en nuestros días, que han cumplido tal condena.

El nazismo alemán, la Unión Soviética o la China comunista son meridianos ejemplos de la profunda reflexión que hace Tzvetan Todorov (2002), siguiendo a autores como Primo Levi, víctima del holocausto:

Los regímenes totalitarios del siglo XX revelaron la existencia de un peligro antes insospechado: el de un completo dominio sobre la memoria. No es que en el pasado se hubiera ignorado la destrucción sistemática de los documentos y monumentos, lo que supone un modo brutal de orientar la memoria de toda la sociedad. Sabemos, por poner un ejemplo alejado de nosotros en el tiempo y en el espacio, que el emperador azteca Itzcoatl, a comienzos del siglo XV, ordenó hacer desaparecer las estelas y los libros para poder recomponer a su modo la tradición; los conquistadores españoles, un siglo más tarde, se empeñaron a su vez en quemar y hacer desaparecer las huellas que atestiguaban la antigua grandeza de los vencidos. Pero, al no ser totalitarios, esos regímenes solo la emprendían con los depósitos oficiales de la memoria, dejando sobrevivir muchas de sus otras formas, por ejemplo, los relatos orales o la poesía. Tras haber comprendido que la conquista de las tierras y los hombres pasa por la de la información y la comunicación, las tiranías del siglo XX sistematizaron su dominio sobre la memoria e intentaron controlarla hasta en sus más secretos rincones. (p. 139)

En los primeros meses de 2015, los noticieros televisivos de todo el mundo mostraron las imágenes atroces de la destrucción sistemática de una parte del 
patrimonio milenario por parte de los yihadistas, acción calificada de "crimen de guerra" por la Unesco.

Sobre todo tipo de totalitarismo, pensemos también en la conocida obra de George Orwell, 1984 - ya considerada un clásico, pese a ser escrita en 1948 y publicada al año siguiente-, con la alegoría del gran hermano y su impresionante ficción de base tan real, tan histórica $y$, al tiempo, tan contemporánea. Tan hiriente.

Masterman (1993), por su parte, centrado ya en los medios de comunicación en sí mismos, aboga por el hecho de que se amplíe "la conciencia crítica" (p. 286), y se desarrollen, de forma coherente, programas educativos que fomenten la autonomía. Los acontecimientos, pasados o presentes, permiten considerar los medios de comunicación auténticas “empresas de concienciación”. Entiende este autor que hay razones para que se preste la atención suficiente a la educación audiovisual y mediática, dada su prioridad para la sociedad y, por lo tanto, para la escuela:

1. El elevado índice de consumo de medios y su saturación.

2. La importancia ideológica de los medios y su influencia como empresas de concienciación.

3. El aumento de la manipulación y fabricación de la información y su propagación por los medios.

4. La creciente penetración de los medios en los procesos democráticos fundamentales.

5. La creciente importancia de la comunicación e información visuales (y de internet).

6. La importancia de educar a los alumnos para que hagan frente a las exigencias del futuro.

7. El vertiginoso incremento de las presiones nacionales e internacionales para privatizar la información.

La comunicación constituye una innegable herramienta para el desarrollo y el cambio social, por lo que su presencia en las aulas no universitarias está plenamente justificada. Se defiende lo que cabe denominar "paradigma de la representación" como la mejor forma de apoyar, mediante el trabajo analítico y la actividad práctica, la interpretación de los contenidos mediáticos, y de efectuar una lectura crítica de la información, de internet y de todos los canales, sin olvidar ninguna de las dimensiones afectadas: carga simbólica, trasfondo ideológico, aspectos estéticos, el propio proceso de producción informativa, coyuntura en la que se realiza la presentación, la dotación de sentido por parte del receptor... Será la mejor manera de avanzar desde la información hasta el conocimiento, 
desde la actualidad efímera representada por los medios hasta la memoria duradera $-\mathrm{y}$, digámoslo una vez más, crítica - construida por los hombres.

\section{Referencias}

Aróstegui, J. (2004). Retos de la memoria y trabajos de la historia. Pasado y memoria. Revistas de Historia Contemporánea, (3), 5-58.

Baer, A. (2005). El testimonio audiovisual. Imagen y memoria del Holocausto. Madrid: Centro de Investigaciones Sociológicas.

Benedetti, M. (2017). ¿Cosecha de la nada? Alicante: Biblioteca Virtual Miguel de Cervantes. Recuperado de http://www.cervantesvirtual.com/nd/ ark:/59851/bmck66j4

Cruz, M. (2005). Las malas pasadas del pasado. Identidad, responsabilidad, historia. Barcelona: Anagrama.

García-Gutiérrez, A. (1994). Otra memoria es posible. Estrategias descolonizadoras del archivo mundial. Buenos Aires: La Crujía.

García-Gutiérrez, A. y Martínez-Ávila, D. (Septiembre-octubre de 2014). Formación crítica de documentalistas en medios de comunicación. El profesional de la información, 23(5), 493-500.

Gitlin, T. (2005). Enfermos de información. De cómo el torrente mediático está saturando nuestras vidas. Barcelona: Paidós.

Kandel, E. (17 de mayo de 2007). Secretos de la memoria. El Cultural, p. 28. Recuperado de http://www.elcultural.com/revista/ciencia/Secretos-dela-memoria/20558

Masterman, L. (1993). La enseñanza de los medios de comunicación. Madrid: De la Torre.

Proust, M. (2016). En busca del tiempo perdido. Madrid: Alianza.

Rodríguez, A. (23 de noviembre de 2005). Estos días azules... El País, p. 18. Recuperado de https://elpais.com/diario/2005/11/23/andalucia/1132701730_850215.html

Saramago, J. (2001). Prólogo. En J. J. Téllez, Moros en la costa (p. 12). Madrid: Debate.

Schacter, D. L. (1999). En busca de la memoria. El cerebro, la mente y el pasado. Barcelona: Ediciones B.

Semprún, J. Viviré con su nombre, morirá con el mío. Barcelona: Tusquets. 
Temprano, E. (2002). El poder del secreto. Barcelona: Ariel.

Terán, O. (2000). Pensar la memoria. Recuperado de http://www.oei.org.ar/edumedia/pdfs/T09_Docu1_Pensarlamemoria_Teran.pdf

Todorov, T. (2002). Memoria del mal, tentación del bien (indagación sobre el siglo $X X)$. Barcelona: Península.

Vidal-Beneyto, J. (30 de diciembre de 2006). Demos también buenas noticias. El País, p. 8. Recuperado de https://elpais.com/diario/2006/12/30/internacional/1167433216_850215.html 
